\title{
Investigation of Different Botanical Origin of Honey Types with Respect to Food Safety
}

\author{
Aziz Gül ${ }^{1}$, Nuray Şahinler ${ }^{2}$ \\ ${ }^{1}$ Washington State Univ. Dep of Entomology, Pullman, USA \\ ${ }^{2}$ Faculty of Agriculture the University of Uşak. Uşak, TURKEY \\ aziz.gul@wsu.edu
}

\begin{abstract}
In this research, antibiotic (sulfamethazine, tetracycline, streptomycin), pesticides (amitraz, coumaphos, fluvalinate) and naphthalene and phosphine residues in 210 honey samples collected from 7 different geographic regions of Turkey were investigated. Accordingly, in the investigations conducted during 2007, out of 210 analyzed honey samples, 92 samples tested positive for antibiotic, 19 samples tested positive for pesticides, 7 samples tested positive for naphthalene and 11 samples tested positive for phosphine residue. Also, antibiotic, pesticides and naphthalene residues were not found in 92 samples out of 210. The obtained results from the study confirmed the routine use of antibiotics and pesticides by beekeepers for the control of certain honey bee diseases and parasites. The results show that some beekeepers in Turkey used antibiotics and pesticides whereas some beekeepers did not use these veterinary drugs. Generally, the risk of residue remaining in the honey in not high and could be reduced with the use of licensed for honey bee veterinary drugs, the correct use of these veterinary drugs and correct application of these prescribed treatment against honey bee disease.
\end{abstract}

Keywords: honey, residue, pesticide, antibiotic, food safety

\section{INTRODUCTION}

Honey is a semi-liquid product, which contains a complex mixture of carbohydrates; mainly glucose and fructose; other sugars are present in trace amounts, depending on floral origin. Moreover, organic acids, lactones, amino acids, minerals, vitamins, enzymes, pollen, wax, and pigments are also present (Fallico, Zappalà, Arena, \& Verzera, 2004) in honey. Honey is generally considered a natural and healthy product. The addition of additives or conserving agents to honey is not necessary. However, the problem of residues of antibiotics and sulphonamides in honey was mentioned in some articles last year (Reybroeck, 2003). Sulphonamides and antibiotics are globally used in beekeeping practices for the control of honeybee diseases, particularly American and European foulbrood (Gallina, Benetti, Biancotto, \& Baggio, 2005). Use of these antibiotics may be responsible for the presence of residues in honey. Also, The Galleria mellonella is huge problem for beekeeper who lives in long-term warm places. Beekeepers have been attempting to control wax moth populations in many ways and beekeepers often use a similar fumigation method to protect stored combs against wax moths(Tsegaye, Wubie, Eshetu, \& Lemma, 2014).

Honey, as a natural product, should be free of chemicals used against pests or any other condition. The use of insecticides can lead to the poisoning of all pollinators including honey bees. The use of chemicals such as insecticides can lead to a decrease in all insect population, including beneficial insect population; the reduction. to a significant loss in a beekeepers' income. Basically, the main purposes for monitoring bee products are consumer health protection, international commercial competition, and better product quality (Al-Waili, Salom, Al-Ghamdi, \& Ansari, 2012). 
Investigation of Different Botanical Origin of Honey Types with Respect to Food Safety

It has been reported that there are 3 millions cases of pesticide poisoning each year and which result in up to 220,000 human deaths, primarily in developing countries. The use of pesticides is often caused by overdose, and unintended to exposure to other organisms in the general area where pesticides are applied (FAO, 2014; Sarwar, 2015).

Regarding European Legislation (EEC Regulation 2377/90 and amendments), the use of antibiotics is not allowed in apiculture: no MRLs (Maximum Residue Limits) are fixed for antibiotics in honey (Fussell et al., 2012; Reybroeck, 2003). Antibiotics used in honeybee practice are illegal in the European Union (EU). Therefore, in some countries like Sweden, UK, and Belgium; antibiotic limits have been determined by national law: between 0.01 and 0.05 ppb (Seğmenoğlu \& Baydan, 2012). In some countries outside the EU, the use of tetracycline, sulphonamides, and other antibiotics has been legalized for the treatment of bacterial diseases. The presence of Varroa mite in honey bee colonies has lead to the necessity of periodic chemical treatments against the Varroa mite that has increased the risk of the contamination of honey. Detection of residues in honey has become a growing concern in recent years, especially as these compounds may diminish the beneficial properties of honey and other honey bee products. Also, if over the residue limits (MRLs), such products may pose a serious threat to human health (Eissa, El-sawi, \& Zidan, 2014).

Segmenoğlu (2013) revealed that roughly $90 \%$ of all analyzed honey samples in 2011 and $96.2 \%$ in 2012 were streptomyocin (antibiotic) residue free. Streptomycin residue has decreased dramatically from 10\% to 3.8\% in honey sample that were analyzed in two consecutive years.

All residues like antibiotics and pesticides in honey have become a major consumer concern. Especially, because some classes of antibiotic drugs have the potential to produce toxic reactions in consumers while others are able to produce allergic or hypersensitivity reactions. Children, and indeed any young and developing organisms, are particularly vulnerable to the harmful effects of pesticides. Even very low levels of exposure during development may have adverse health effects. The aim of this study is to investigate some of the chemicals that are used in beekeeping activities to treat honey bees and the residues that result with respect to food safety in Turkey.

\section{Materials AND METHODS}

\section{Honey samples}

For experiments, 210 liquid honey samples were collected in 2007-2008 from 7 different regions of Turkey. Honey samples were from the following regions; 59 samples from Black Sea Region, 42 samples from Aegean Region, 26 samples from East Anatolia Region, 28 samples from Mediterranean Region, 21 samples from Mid Anatolia Region, 18 samples from Marmara Region, 6 samples from South-East Anatolia and 10 samples from market honey (unknown regions of Turkey). Number of samples collected were proportionate to the population of beekeepers in each region comparatively. Excel software generated the total number of samples to collect by region given the total number of registered beekeepers who contribute to production as reported by the Turkish Beekeeper Associations.

\section{Antibiotic Analysis}

The antibiotic analysis diagnosed in the honey samples was by Charm II honey Assay (Martel, Zeggane, Drajnudel, Faucon, \& Aubert, 2006; Münstedt, ThortenRademacher \& Petz, 2005; Reybroeck, 2003). Standard solutions $(10 \mathrm{ppb})$ of Sulfamethazine, Tetracycline, and Streptomycin were used as a reference to determine the residue limit point in the honey samples. The Charm II process determined which of the honey samples contained $\geq 10$ $\mathrm{ppb}$ antibiotic residue level. Those samples that tested positive for (more than) $10 \mathrm{ppb}$ were then evaluated for antibiotic residue levels by the HPLC-FLOURESAN. 
Investigation of Different Botanical Origin of Honey Types with Respect to Food Safety

The positive samples (above $\geq 10 \mathrm{ppb}$ ) was analyzed HPLC- FLOURESAN detector using the ODS (C18, $5 \mu, 150$ mm x 4,6 mm (H5 ODS Hichrom), (\% 90: 10)) colon. HPLC analysis condition was fixed (as/at) : Flow $0.7 \mathrm{ml} /$ $\mathrm{dk}$, Mobil phase (mobile phase A: $1 \%$ acetonitrile, mobile phase 2: $80 \%$ acetonitrile), temperature of colon and reactor: $45 \stackrel{\circ}{\circ}$, injected sample: $70 \mu$, and time $36 \mathrm{~min}$; FLOURESAN detector condition was fixed as : excitation wavelength 400, and Emission wavelength 495 nm (Martel et al., 2006; Münstedt, ThortenRademacher \& Petz, 2005; Reybroeck, 2003).

\section{Pesticides Residue Analysis}

Specifically, the pesticide residue analysis determined the presence of the three commonly used pesticides in the varroa mite struggle: Amitraz, Coumaphos, Fluvalinate. A GC-MS (Hewlett Packard Gas Chromatograph 6890 Series Plus linked to Hewlett-Packard 6890 Mass Spectrometer) system was used for this pesticide residue analysis. The capillary column ( $25 \mu \mathrm{m}$ thickness, $0.25 \mathrm{~mm}$ diameter, $30 \mathrm{~m}$ length) and Helium carrier gas ( $1 \mathrm{ml} /$ min velocity , $0,5 \mu \mathrm{l}$ injection volume, and $300^{\circ} \mathrm{C}$ injection temperature; column temperatures, $40^{\circ} \mathrm{C} 1$ minute wait, $250^{\circ} \mathrm{C} 10$ minute wait) were used on the GS-MS system (Maver \& Poklukar, 2003; Tsipi, Triantafyllou, \& Hiskia, 1999).

\section{Naphthalene and Phosphine Gases Analysis}

Naphthalene and Phosphine analysis was carried out with GS-MS (Hewlett Packard Gas Chromatograph 6890 Series plus linked to Hewlett-Packard 6890 Mass Spectrometer) and Headspace system (Oven temperature 80 ${ }^{\circ} \mathrm{C}$, Injection unit $90{ }^{\circ} \mathrm{C}$, transfer Line $100{ }^{\circ} \mathrm{C}$ ) GC- Cycle time: $45 \mathrm{~min}$, Vial Eq. Time, Pres time: 0.05 min, Loop till time: $0.02 \mathrm{~min}$, Loop eq. time: $0.5 \mathrm{~min}$, Injection time: $0.5 \mathrm{~min}$ (Sakata et al., 2004).

\section{RESULT AND DISCUSSION}

\section{Antibiotic Analysis}

The means and ranges of residue values of antibiotic and pesticides in honey samples according to regions summarized in Table 1. Antibiotic residues in honey samples were positive in Mediterranean, Aegean, East Anatolia, Black Sea, Mid Anatolia, Marmara South-East Anatolia, and market honeys 6, 8, 9, 40, 16, 6, 3 and 4 out of 210 samples respectively. The highest number of samples that tested positive for antibiotic residues were found in the Black Sea Region ( 40 samples out of 59 samples in the Black Sea Region) as compared to the others regions (Table 1).

Sulphamethazine positive residues were found in 7 regions, a total of 60 samples out of 210 samples were above the MRL (according to Turkish food codex $0 \mathrm{ppm}$ ). A total 150 samples were negative for sulfamethazine residues. In other words, 150 samples were appropriate to EU regulation (2001/110/EC) and Turkish Food Codex. Positive Tetracycline residues were found above the MRL in 2 regions (Black Sea, Mid Anatolia); only in 7 out of 210 samples (According to Turkish food codex $10 \mathrm{ppm}$ ); a total of 203 samples were negative for tetracycline residues. In other words, 203 samples were appropriate to EU regulation (2001/110/EC) and Turkish food codex. Streptomycin residues were found above the MRL in 6 regions (Aegean Region except all regions); a total of 25 out of 210 samples (According to Turkish Food Codex 0 ppm). Thus, 185 honey samples were negative for streptomycin and appropriate to EU regulation (2001/110/EC) and Turkish food codex. Reybroeck (Reybroeck, 2003) reported that honey samples from the Belgian market contained residues. The residues most frequently found were: streptomycin, 51 out of 108 samples (47.2\%); tetracyclines 29 out of 98 samples (29.6\%); sulphonamides, 31 out of 98 samples (31.6\%); and chloramphenicol, 40 out of 85 
Investigation of Different Botanical Origin of Honey Types with Respect to Food Safety

samples (47.1\%). Gallina et al. (2005) reported that antibiotic residue analyses performed in honey samples during the 2000-2003 period resulted in 35 samples out of 212 samples testing positive for antibiotics such as sulphonamide, streptomycin and tylosin.

\section{Pesticides Analysis}

In terms of pesticide residue in honey samples from the Mediterranean, Aegean, East Anatolia, Black Sea, Mid Anatolia, Marmara, South-East Anatolia region and markets honey, each region was found positive by a number of $0,3,3,5,3,2,0$ and 3 out of 210 samples respectively. Thus, the Mediterranean and South East Anatolian region were the safest in terms of pesticide residue in the honey samples collected; pesticide residue was detected in 0 of 28 samples and 0 of 6 South East Anatolia respectively. The number of honey samples containing pesticide residue was the highest in the Black Sea Region; pesticide residue was detected in 5 out of 59 samples.

Amitraz is a fat-soluble pesticide compound which is not very stable in honey. It degrades almost completely into several decomposed metabolites after 3-4 weeks (Maver \& Poklukar, 2003). It was found that 16 out of 210 samples that contained amitraz residue in five (Aegean, East Anatolia, Black Sea, Mid Anatolia, Marmara) regions were above the MRL. However, 194 samples were within the standard of $200 \mathrm{ppb}$ allowed by the EU regulation (2001/110/EC). A total 3 out of 210 samples of honey from 3 regions (Aegean, Black Sea, and East Anatolia region) were found positive for coumaphos pesticide at a level above the MRL. At the same time, 207 samples were within the standard of $100 \mathrm{ppb}$ allowed by EU regulation (2001/110/EC) and Turkish Food Codex. All honey samples in all regions (210 samples) were fluvalinate residue free. All collected honey samples from all 7 regions of Turkey were found safe in terms of fluvalinate residue. In the other words, none of the beekeepers used fluvalinate to struggle with mites in the 2006-2007 sample period in Turkey.

Maver and Poklular (Maver \& Poklukar, 2003) reported that positive amitraz and coumaphos residues were found in honey samples from Slovenia at a level of $0.02 \mathrm{mg} / \mathrm{kg}$ and $0.022 \mathrm{mg} / \mathrm{kg}$ respectively in 5 honey samples out of total 19 honey samples. They did not analyze the collected samples for fluvalinate residue. Sabatini et al., (Sabatini, Carpana, Serra, \& Colombo, 2003) reported that pesticides residue levels above MRL for coumaphos were found in 30 (13.9\%) samples out of 215 and in 1 (1.4\%) sample out of 71 for fluvalinate from Italian honey.

It was reported by Garcia et al., (1996) that out of 221 honey samples produced during 1988-1991 in Spain; 19, 32 and 39 samples were found positive for amitraz, coumaphos and fluvalinate respectively. Fernandez et al., (1997) reported that pesticide residues out of 101 honey samples from Spain; 16 and 11 samples were found positive for bromoplate and fluvalinate respectively.

Sabatini etal., (2003) reported that pesticides residue levels above MRL for coumaphos were found in 30 (13.9\%) samples out of 215 and in 1 (1.4\%) sample out of 71 for fluvalinate from Italian honey. Lopez et al., (2014) reported that of 62 columbian honey samples, $52.2 \%$ were positive for organochlorine and organophosphorus pesticides and $47.8 \%$ were negative. A total in $5 \%$ of all honey samples had residue levels were above MRL.

\section{Naphthalene Analysis}

Naphthalene residues in honey samples were found only in 3 regions (Aegean 4, Mid Anatolia 1, and Central Anatolia 1) and only in $3 \%$ of total samples. However, the phosphine residue were detected in 11 honey samples (5.2\%) out of 210 around all 7 regions. Phosphine is usually used by other industries, especially in the big wheat storages against insects(Nowicki, 1978). The use of the phosphine by beekeeper against Galleria mellonella 
Investigation of Different Botanical Origin of Honey Types with Respect to Food Safety

was detected by this study for the first time in Turkey. Castle et al., (2004) reported that in 49 honey samples collected from markets in England, napthalene was found in one sample, 2\% of total samples. Harizanis et al., (2008) reported that naphthalene was found in traceable amounts in $78.9 \%$ of the samples, but only $5.6 \%$ of them contained concentrations above the MRL, which indicates the use of pre-contaminated honeycomb foundations or built combs.

\section{Conclusion}

These results show that residues do not represent a risk for food safety in the majority samples. Residue levels in the honey samples above the MRL, were detected. For amitraz, 13 out of 210 samples (6.5\%), for coumapous 3 out of 210 (1.5\%), for Naphthalene 1 out of 210 samples (0.5\%), for Sulphamethazine 59 out of 210 samples (29.5\%), for Tetracycline 7 out of 210 samples (3.5\%), and Streptomycin 22 out of 210 samples (11\%), for a total of 210 samples of honey. However, veterinary drug residues were not found in a total of 105 samples (52.5\%) of honey collected from all regions.

The results obtained confirm that antibacterial drugs and pesticides are frequently used by beekeepers for the control of honey bee diseases and Varroa mite. Generally, the risk of the presence of residues in honey samples is not high and could easily be reduced with the correct use of the veterinary drugs, used licensed veterinary drug for bee and correct application of the prescribed medical against the bee diseases. The use of antibiotics that used to against honey bee disease were forbidden completely by the new regulations of Turkish Standard in Turkey. Limit of the antibiotic residue should be " 0 " by the analysis of it in honey samples. Therefore, Over the last decade, it is seen that antibiotics, (like streptomycin), are being used much more consciously and antibiotic residues in honey is currently decreasing in beekeeping industry in Turkey.

Today, in many facets of agricultural industry, the extreme use of antibiotics and pesticides has resulted in antibiotic and pesticide resistant bacteria, fungi and pests. This has become a major clinical and public health problem within the lifetime of most people living today throughout the world.

Essential to preventing the spread and abundance of pesticides and antibiotics in all agricultural industries is education. Although this study shows that many anti-biotics and pesticides are within the limit understood as "safe," organisms are still becoming resistant to these chemicals. By the forbidden of antibiotics in beekeeping, the decrease in antibiotics and pesticides use in beekeeping in Turkey in the last decades is evident in the residue levels in the honey samples, other chemicals such as oxalic acid, lactic acid and formic acid, encouraged by the Agricultural Ministry and Türkish Beekeeping Assosiation in Turkey, because of studies such on honey, may have lead to decreases in the use of anti-biotics and pesticides in beekeeping.

\section{REFERENCES}

Al-Waili, N., Salom, K., Al-Ghamdi, A., \& Ansari, M. J. (2012). Antibiotic, Pesticide, and Microbial Contaminants of Honey: Human Health Hazards. The Scientific World Journal, 2012(Table 1), 1-9. https://doi. org/10.1100/2012/930849

Castle, L., Philo, M. R., \& Sharman, M. (2004). The analysis of honey samples for residues of nitrobenzene and petroleum from the possible use of Frow mixture in hives. Food Chemistry, 84(4), 643-649. https://doi. org/http://dx.doi.org/10.1016/j.foodchem.2003.07.027

Eissa, F., El-sawi, S., \& Zidan, N. E. (2014). Determining Pesticide Residues in Honey and their Potential Risk to Consumers. Polish Journal of Environmental Studies, 23(5), 1573-1580.

American Research Journal of Agriculture

Page 5 
Investigation of Different Botanical Origin of Honey Types with Respect to Food Safety

Fallico, B., Zappalà, M., Arena, E., \& Verzera, A. (2004). Effects of conditioning on HMF content in unifloral honeys. Food Chemistry, 85(2), 305-313. https://doi.org/10.1016/j.foodchem.2003.07.010

FAO. (2014). Food and Agriculture Organization, the international code of conduct on pesticide management.

Fernandez Muiño, M. A., Sancho, M. T., Simal-Gandara, J., Creus-Vidal, J. M., Huidobro, J. F., \& Simal-Lozano, J. (1997). Acaricide residues in honeys from Galicia (N.W. Spain). Journal of Food Protection, 60(1), 78-80.

Fussell, R. J., Heinrich, K., Dickinson, M., Wilkins, S., Roelofs, V., Murray, A., ... Sharman, M. (2012). Investigation into the experimental protocols required to determine maximum residue limits (MRLs) in honey. Drug Testing and Analysis, 4(SUPPL.1), 118-124. https://doi.org/10.1002/dta.1360

Gallina, A., Benetti, C., Biancotto, G., \& Baggio, A. (2005). Antibiotics Residues in Honey : Validation Procedure, 40(October), 45-49.

Garcia, M. A., Fernandez, M. I., Herrero, C., \& Melgar, M. J. (1996). Acaricide residue determination in honey. Bulletin of Environmental Contamination and Toxicology, 56(6), 881-887.

Harizanis, P.-C., Alissandrakis, E., Tarantilis, P.-A., \& Polissiou, M. (2008). Solid-phase microextraction/gaschromatographic/mass spectrometric analysis of $\mathrm{p}$-dichlorobenzene and naphthalene in honey. Food Additives \& Contaminants: Part A, 25(10), 1272-1277. https://doi.org/10.1080/02652030802007546

Martel, a-C., Zeggane, S., Drajnudel, P., Faucon, J.-P., \& Aubert, M. (2006). Tetracycline residues in honey after hive treatment. Food Additives and Contaminants, 23(3), 265-273. https://doi. org/10.1080/02652030500469048

Maver, L., \& Poklukar, J. (2003). Coumaphos and amitraz residues in Slovenian honey, 38, 54-57.

Münstedt, ThortenRademacher, E., \& Petz, M. (2005). Hplc , Charm Ii and Elisa : Advantages and Disadvantages for the Analysis of Tetracyclines in Honey, 40, 5-9.

Nowicki, T. W. (1978). Gas-liquid chromatography and flame photometric detection of phosphine in wheat. Journal - Association of Official Analytical Chemists, 61(4), 829-836.

Reybroeck, W. (2003). Residues of Antibiotics and Sulphonamides in Honey on. Apiacta, 38, 23-30.

Rodríguez López, D., Ahumada, D. A., Díaz, A. C., \& Guerrero, J. A. (2014). Evaluation of pesticide residues in honey from different geographic regions of Colombia. Food Control, 37(1), 33-40. https://doi.org/10.1016/j. foodcont.2013.09.011

Sabatini, A. G., Carpana, E., Serra, G., \& Colombo, R. (2003). Presence of Acaricides and Antibiotics in Samples of Italian Honey, 38, 46-49.

Sakata, S. K., Taniguchi, S., Rodrigues, D. F., Urano, M. E., Wandermüren, M. N., Pellizari, V. H., \& Comasseto, J. V. (2004). Development of a static headspace gas chromatographic/mass spectrometric method to analyze the level of volatile contaminants biodegradation. Journal of Chromatography A, 1048(1), 67-71. https:// doi.org/http://dx.doi.org/10.1016/j.chroma.2004.07.021

Sarwar, M. (2015). The Dangers of Pesticides Associated with Public Health and Preventing of the Risks. International Journal of Bioinformatics and Biomedical Engineering, 1(2), 130-136.

Seğmenoğlu, M. S. (2013). Ballarda Streptomisin Kalıntı Taraması, 3(1), 15-17.

American Research Journal of Agriculture

Page 6 
Investigation of Different Botanical Origin of Honey Types with Respect to Food Safety

Seğmenoğlu, M. S., \& Baydan, E. (2012). Ballarda Rastlanabilen İlaç Kalıntıları ve Bulaşanlar. Türkiye 2. Ekolojik Tarım Sempozyumu, (3), 24-28.

Tsegaye, A., Wubie, A. J., Eshetu, A. B., \& Lemma, M. (2014). Evaluation of different non-chemical wax moth prevention methods in the backyards of rural beekeepers in the North West dry land areas of Ethiopia. IOSR Journal of Agriculture and Veterinary Science, 7(3), 29-36. https://doi.org/10.9790/2380-07312936

Tsipi, D., Triantafyllou, M., \& Hiskia, A. (1999). Determination of organochlorine pesticide residues in honey, applying solid phase extraction with RP-C18 material[dagger]. Analyst, 124(4), 473-475. https://doi. org/10.1039/A809724K

Citation: Aziz Gül, Nuray Şahinler, "Investigation of Different Botanical Origin of Honey Types with Respect to Food Safety". American Research Journal of Agriculture, V3, I1; pp:1-7

Copyright (C) 2017 Aziz Gül, Nuray Şahinler, This is an open access article distributed under the Creative Commons Attribution License, which permits unrestricted use, distribution, and reproduction in any medium, provided the original work is properly cited. 